\title{
BMJ Open Comparing Antonovsky's sense of coherence scale across three UK post-industrial cities
}

\author{
David Walsh, ${ }^{1}$ Gerry McCartney, ${ }^{2}$ Sarah McCullough, ${ }^{2}$ Duncan Buchanan, ${ }^{3}$ \\ Russell Jones ${ }^{1}$
}

To cite: Walsh $D$,

McCartney G, McCullough S, et al. Comparing

Antonovsky's sense

of coherence scale across

three UK post-industrial

cities. BMJ Open 2014;4:

e005792. doi:10.1136/

bmjopen-2014-005792

- Prepublication history for this paper is available online. To view these files please visit the journal online (http://dx.doi.org/10.1136/ bmjopen-2014-005792)

Received 26 May 2014 Revised 19 August 2014 Accepted 20 August 2014

CrossMark

\footnotetext{
${ }^{1}$ Glasgow Centre for Population Health, Glasgow, UK

${ }^{2}$ NHS Health Scotland, Glasgow, UK

${ }^{3}$ ISD Scotland, Edinburgh, UK
}

Correspondence to Dr David Walsh; david.walsh@drs.glasgow. gov.uk

\section{ABSTRACT}

Objectives: High levels of 'excess' mortality (ie, that seemingly not explained by deprivation) have been shown for Scotland compared to England and Wales and, especially, for its largest city, Glasgow, compared to the similarly deprived English cities of Liverpool and Manchester. It has been suggested that this excess may be related to differences in 'Sense of Coherence' (SoC) between the populations. The aim of this study was to ascertain whether levels of SoC differed between these cities and whether, therefore, this could be a plausible explanation for the 'excess'.

Setting: Three post-industrial UK cities: Glasgow, Liverpool and Manchester.

Participants: A representative sample of more than 3700 adults (over 1200 in each city).

\section{Primary and secondary outcome measures:}

SoC was measured using Antonovsky's 13-item scale (SOC-13). Multivariate linear regression was used to compare SoC between the cities while controlling for characteristics (age, gender, SES etc) of the samples. Additional modelling explored whether differences in SoC moderated city differences in levels of selfassessed health (SAH).

Results: SoC was higher, not lower, among the Glasgow sample. Fully adjusted mean SoC scores for residents of Liverpool and Manchester were, respectively, $5.1(-5.1(95 \% \mathrm{Cl}-6.0$ to -4.1$))$ and $8.1(-8.1(-9.1$ to -7.2$))$ lower than those in Glasgow. The additional modelling confirmed the relationship between SoC and SAH: a 1 unit increase in SoC predicted approximately $3 \%$ lower likelihood of reporting bad/very bad health $(\mathrm{OR}=0.97(95 \% \mathrm{Cl} 0.96$ to 0.98)): given the slightly worse SAH in Glasgow, this resulted in slightly lower odds of reporting bad/ very bad health for the Liverpool and Manchester samples compared to Glasgow.

Conclusions: The reasons for the high levels of 'excess' mortality seen in Scotland and particularly Glasgow remain unclear. However, on the basis of these analyses, it appears unlikely that a low SoC provides any explanation.

\section{INTRODUCTION}

Excess mortality in Scotland and Glasgow

Previous research has suggested that the higher levels of mortality recorded in

\section{Strengths and limitations of this study}

- This is the first time Antonovsky's Sense of Coherence $(\mathrm{SoC})$ has been measured for these three, important, post-industrial UK cities, using a scale deemed reliable and valid.

- This has, therefore, enabled the first investigation of the proposal that differences in SoC may contribute to higher Scottish mortality, as well allowing the first analyses of SoC and self-assessed health in these settings.

- The analyses have been based on representative samples of the cities' adult populations, and employed appropriate statistical methodologies to ensure all reported differences between the cities were independent of the characteristics of the survey samples.

- However, the analyses have been based on cross-sectional survey data which do not, therefore, allow any measure of impact or otherwise, on individuals' subsequent mortality (an important component of the original hypothesis).

- Any population survey is unlikely to be entirely representative of its target population: it is probable, therefore, that not all sections of society are represented within the collected data.

Scotland compared to the rest of the UK, and particularly in Glasgow (the country's largest city) compared to other, similar, UK cities, cannot be explained entirely in terms of poverty and socioeconomic deprivation alone. After adjustment for area deprivation, mortality in Scotland was $8 \%$ higher than in England and Wales in 2001 (with much higher levels of 'excess' mortality for specific causes such as lung cancer (26\% higher) and suicide $(40 \%))$, ${ }^{1}$ while premature mortality (under 65 years) in Glasgow has been shown to be $30 \%$ higher than in the identically deprived UK cities of Liverpool and Manchester (with deaths at all ages almost $15 \%$ higher). ${ }^{2}{ }^{3}$ This city excess has been shown for all adult age groups, both sexes and across different neighbourhood types 
(deprived and non-deprived). Importantly, the excess is increasing over time. Similar levels of excess have been shown in analyses based on individual socioeconomic status (SES; rather than area deprivation) ${ }^{45}$ and when controlling for a range of biological and behavioural risk factors. ${ }^{6}$

A considerable number of theories have been proposed to explain Scotland's excess poor health compared to England and Wales, and in particular Glasgow's compared to Liverpool and Manchester. ${ }^{78}$ It has been specifically hypothesised, including within official government reports ${ }^{9} 10$ that the excess may be related to differences in 'Sense of Coherence' between the populations.

\section{Sense of Coherence}

Sense of Coherence (SoC) is a theory developed by the American-Israeli sociologist Aaron Antonovsky. ${ }^{11} 12$ Emerging from his work around the concept of salutogenesis (a focus on the mechanisms that promote and support good health, in contrast to pathogenesis, the factors that create disease), and in particular the relationship between health and stress, the theory seeks to capture the extent to which people can manage, or be resilient to, the negative effects of stress on health and well-being. It was famously developed from his studies of women who survived Nazi concentration camps in the Second World War. It is made up of three components: comprehensibility (the extent to which events in one's life can be readily understood and predicted), manageability (having the necessary skills and resources to manage and control one's life) and meaningfulness (there being a clear meaning and purpose to life), ${ }^{12}$ of which the third was viewed by Antonovsky to be the most important. Two versions of the SoC scale were created by Antonovsky, one with 29 questions (SOC-29) and a later one with 13 questions (SOC-13: the one employed in the analyses presented here), although a considerable number of modified versions of both have also been used. ${ }^{13}$ Overall the measure has been deemed to be a 'reliable, valid and cross-culturally applicable instrument', ${ }^{13}$ and has been shown to be significantly associated with a wide variety of outcomes, in particular: various measures of quality of $\operatorname{life}^{1415}$ and perceived health status; ${ }^{16}$ mental health, ${ }^{16}$ 16a (eg depression, hopelessness, ${ }^{13}$ 17-20 anxiety, post-traumatic stress symptoms, ${ }^{21}$ psychiatric disorders ${ }^{22}$ and suicide ${ }^{23}$ ); crime ${ }^{24}$ risk of tobacco use ${ }^{25}$ and alcohol and drug problems. ${ }^{26} 27$ Some reviewers have questioned its association with physical health, ${ }^{17}$ citing considerably mixed evidence. However, it has been shown to be significantly associated with, for example, circulatory health problems, ${ }^{28}$ diabetes, ${ }^{29}$ post-surgery recovery ${ }^{30} 31$ and a recent (2008) UK study of almost 20000 individuals suggested that a strong SoC was associated with a $20 \%$ reduction in allcause mortality. ${ }^{32}$

Given the above evidence of links to a variety of health-related outcomes, it has been hypothesised that SoC may be lower among the Scottish and Glaswegian populations. ${ }^{9} 10$ The aim of the analyses presented here was to establish whether this was the case for residents of Glasgow compared to those of the similar English cities, Liverpool and Manchester.

\section{METHODS}

\section{Population survey}

A population survey of Glasgow, Liverpool and Manchester was carried out in 2011. Full details of the survey design and implementation are available elsewhere. ${ }^{33}$ Briefly, a stratified clustered random probability sample design was employed, from which face-to-face 'in home' household interviews were undertaken for a representative sample of more than 3700 adults (over 1200 in each city). The response rate was $55 \%$, ranging from $53 \%$ in Manchester to $58 \%$ in Glasgow (the rate for Liverpool was $55 \%$ ), and from $53 \%$ in the least deprived areas of the three cities to $58 \%$ in the most deprived areas. Data were weighted to ensure they were as representative of the households and cities as possible. ${ }^{\mathrm{i}}$ Representativeness was further assessed by means of comparisons with a range of other survey and administrative data. ${ }^{33}$

SoC-one of seven hypotheses for which data were collected in the survey-was measured using Antonovsky's 13-item scale (SOC-13). The 13 questions are scored from 1 to 7 from which a total SoC score is derived for each respondent. Five of the questions are reverse-coded in the analysis to ensure that in all questions a higher score equates to a higher SoC. ${ }^{\text {ii }}$ Five questions make up the 'comprehensibility' subscale $(2,6,8$, 9 and 11). The 'meaningfulness' subscale is derived from four questions (1, 4, 7 and 12) and the remaining questions (3, 5, 10 and 13) make up the 'manageability' subscale.

\section{Statistical analyses}

SoC scores (and those of the three subscales) were compared between the cities, while controlling for the characteristics of the samples. This was performed by means of a series of multivariate linear regression models. In each, the dependent variable was the SoC (or subscale) score, and the independent variables were the city of residence (Glasgow, Liverpool or Manchester) and the following sample characteristics: age, gender,

\footnotetext{
${ }^{\mathrm{i}}$ In total the weighting comprised six separate steps which overall adjusted for differential response by deprivation decile and 'up-weighted' multiple households, large households, younger ages and men to adjust for the lower probability of sampling in the former two and the lower response rates in the latter two. Separate weights were produced for analysis at city and whole sample level.

${ }^{\text {ii }}$ For example Question 1 in the scale is: 'Do you have the feeling that you don't really care about what goes on around you?', with possible answers ranging from 1 ('Very seldom or never') to 7 ('Very often') These scores are reverse coded so that 7 equates to 'Very seldom or never' (an indication of high SoC) and 1 equates to 'Very often' (indicating low SoC). The questions that are reverse-coded are 1, 2, 3, 7 and 10.
} 
ethnicity, social class/grade, ${ }^{\text {iii }}$ area deprivation quintile, educational attainment, employment status, marital status, health status and length of residence in the city. These variables are defined in table 1 .

Models were built incrementally, but only significant $(\mathrm{p}<0.05)$ variables were included in the final models. All models were run using SPSS statistical software.

Models were run using weighted and unweighted data, with the results of the former reported here (and generally there were very little differences between the regression coefficients obtained for the cities in the weighted compared to the unweighted models).

Interactions between the independent variables (excluding city) were tested for: although some were identified (significant at $\mathrm{p}<0.05$ ), they did not alter the coefficients of the cities (the main focus of the analysis), and so are not reported here. ${ }^{\text {iv }}$

As a number of commentators argue the need for multilevel modelling to explore and distinguish between individual and area influences on health, ${ }^{35-37}$ the main SoC model was also run as a multilevel linear regression model using MLwiN software (V.2.26). There were two levels: individual and neighbourhood (sampling points with an average population size of approximately 300 people $\left.^{33}\right)$. However, there was virtually no difference between results in terms of the coefficients for the cities.

An additional set of models was run to establish whether differences in SoC were associated with differences in levels of self-assessed health (SAH). Previous research into excess poor health in Scotland and Glasgow has emphasised the need to concentrate of outcomes of mortality, given the demographic, socioeconomic and cultural factors that have been shown to influence self-assessment of health between different countries and populations. ${ }^{38-40}$ However, given the evidence cited above linking SoC to a range of adverse health-related outcomes, it was still of interest to know whether this was the case for this representative sample of three UK post-industrial cities. Multivariate logistic regression modelling was employed, with a binary outcome of 'bad' or 'very bad' SAH (two of the five possible answers" to the question 'How is your health in general?') and the same predictor variables listed in table 1 together with smoking ${ }^{\mathrm{vi}}$ (given its relevance to

\footnotetext{
iiiSocial class was assessed by means of approximate 'Social Grade'. Social Grade is the socioeconomic classification used by the Market Research and Marketing Industries, and is used in the analysis of UK Census data. The scale is used for individuals aged 16 and over, classified by the Social Grade of their Household Reference Person (HRP). The categories, derived from occupation, are: A: High managerial, administrative or professional; B: Intermediate managerial, administrative or professional; C1: Supervisory, clerical and junior managerial, administrative or professional; C2: Skilled manual workers; D: Semi and unskilled manual workers; E: unemployed, on state benefits or 'lowest grade workers'.

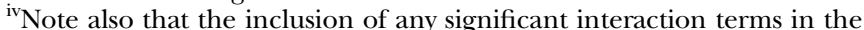
models generally did not increase the amount of variation explained in the models by any great extent.

"The five answers were: very good; good; fair; bad; very bad.
}

the outcome measure) and SoC (included as both a continuous variable).

\section{RESULTS}

Contrary to the suggested hypothesis, SoC was found to be substantially higher, not lower, among the Glasgow sample compared to the samples of the two English cities. Descriptive analyses showed that it was higher overall, and in comparison of all strata of gender, age, area deprivation and social class (data not shown). These findings were confirmed by the modelling analyses. Table 2 shows that adjusting for all differences in the characteristics of the samples, residents of Liverpool were associated with a mean SoC score of 5.1 lower (regression coefficient: -5.05 (95\% CI -6.04 to -4.07$)$ ) than residents of Glasgow, with the adjusted mean score of the Manchester sample being 8.1 lower than that of Glasgow (-8.14 (95\% CI -9.12 to -7.16$)$ ).

Differences between the cities were also seen in the modelling of the comprehensibility (regression coefficient for Liverpool: -2.42 (95\% CI -2.83 to -2.00$)$; Manchester -2.74 (95\% CI -3.15 to -2.32), manageability (Liverpool: -1.37 (95\% CI -1.71 to -1.04 ); Manchester -2.44 (95\% CI -2.77 to -2.11$))$ ), and meaningfulness (Liverpool: -1.23 , (95\% CI -1.58 to $-0.88)$; Manchester -2.93 (95\% CI -3.27 to -2.58$))$ ) scores (data not shown).

The modelling also highlighted the association between SoC and respondents' socioeconomic status (social grade, ${ }^{\mathrm{vii}}$ area deprivation, educational attainment, employment status all featuring as significant $(p<0.05)$ independent variables in the models) as well as marital status (the fully-adjusted model showing higher scores in married respondents than in those who had never been married) and age.

Descriptive analyses showed levels of self-assessed health to be broadly similar across the three cities. The percentages of respondents reporting 'bad' or 'very bad' health in Glasgow, Liverpool and Manchester were $9.6 \%, 8.5 \%$ and $5.9 \%$, respectively, while the percentages reporting 'good' or 'very good' health were $73 \%, 72 \%$ and $75 \%$, with the equivalent figures for those reporting 'fair' health being $17 \%, 19 \%$ and $20 \%$. ${ }^{\text {viii }}$ In the more detailed analyses of the data on bad/very bad SAH by means of multivariate logistic regression residents in Manchester were shown to be approximately $33 \%$ less likely to report such poor health compared to those in

\footnotetext{
${ }^{\mathrm{vi}}$ The smoking variable was categorised as: never/hardly ever smoked (reference category); ex-smoker; occasional smoker; regular smoker

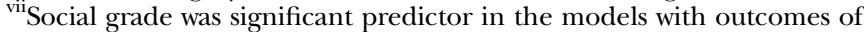
meaningfulness and manageability, but not SoC itself (where area deprivation and other individual SES-related measures explained more of the variation).

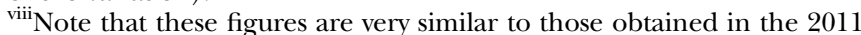
census. For example, the percentages of the total populations of Glasgow, Liverpool and Manchester reporting bad or very bad health in the census was $9 \%, 9 \%$ and $7 \%$ respectively.
} 
Table 1 Independent variables used in regression modelling analyses

\begin{tabular}{|c|c|}
\hline Variable & Categories \\
\hline \multirow[t]{3}{*}{ City of residence } & Glasgow* \\
\hline & Liverpool \\
\hline & Manchester \\
\hline \multirow[t]{2}{*}{ Gender } & Male* \\
\hline & Female \\
\hline \multirow[t]{4}{*}{ Age } & $16-29 *$ \\
\hline & $30-44$ \\
\hline & $45-64$ \\
\hline & 65 and older \\
\hline \multirow[t]{6}{*}{ Social grade } & A (higher managerial, administrative or professional) and \\
\hline & $\mathrm{B}$ (intermediate managerial, administrative or professional) ${ }^{\star} \dagger$ \\
\hline & C1 (supervisory, clerical and junior managerial, administrative or professional) \\
\hline & C2 (skilled manual workers) \\
\hline & D (semi and unskilled manual workers) \\
\hline & E (on state benefits/unemployed/lowest grade workers) \\
\hline \multirow[t]{6}{*}{ Employment status } & Employed $(\mathrm{PT} / \mathrm{FT})^{*}$ \\
\hline & Unemployed \\
\hline & III/disabled \\
\hline & Retired \\
\hline & Looking after home/family \\
\hline & In education/training (PT/FT) \\
\hline \multirow[t]{3}{*}{ Educational attainment } & No qualifications* \\
\hline & Some qualifications, but not degree levelł \\
\hline & 1st degree and above (includes NVQ/SVQ Level 5 or equivalent)§ \\
\hline \multirow[t]{5}{*}{ Deprivation quintileף } & 1 (most deprived) ${ }^{*}$ \\
\hline & 2 \\
\hline & 3 \\
\hline & 4 \\
\hline & 5 (least deprived) \\
\hline \multirow[t]{2}{*}{ Ethnicity } & Not a member of ethnic minority group* \\
\hline & Member of ethnic minority group ${ }^{\star *}$ \\
\hline \multirow[t]{4}{*}{ Marital status } & Never married* \\
\hline & Married/civil partnership \\
\hline & Separated/divorced \\
\hline & Widowed/surviving partner \\
\hline \multirow[t]{2}{*}{ Length of residence (approximate) } & Time in city not known* \\
\hline & Possibly long-term resident†† \\
\hline
\end{tabular}

${ }^{*}$ Denotes reference category.

†Social Grades 'A' and 'B' were combined into one single category because of the very small number of respondents in each city classed as Social Grade 'A'.

¥No degree level qualifications but one of the following categories: O Grade, Standard Grade, O Level, Access 3 Cluster, Intermediate 1 or 2 , GCSE, CSE, Senior Certificate or equivalent; SCE Higher Grade, Higher, Advanced Higher, CSYS, A level, AS Level, Advanced Senior Certificate or equivalent; GNVQ/GSVQ Foundation or Intermediate, NVQ/SVQ Level 1 or 2, SCOTVEC Module, City and Guilds Craft or equivalent; GNVQ/GSVQ Advanced, NVQ/SVQ Level 3, ONC, OND, SCOTVEC National Diploma, City and Guilds Advanced Craft or equivalent; HNC, HND, NVQ/SVQ level 4 or equivalent; Professional qualifications; Other school qualifications not already mentioned (including foreign qualifications); Other postschool but preHigher Education qualifications not already mentioned (including foreign qualifications); Other Higher Education qualifications not already mentioned (including foreign qualifications); Other vocational/work-related qualifications.

$\S$ Full list on questionnaire: First Degree, Postgraduate qualifications, Masters, PhD, NVQ/SVQ Level 5 or equivalent.

TBased on 'income deprivation' in 2005, the measure in previous analyses of deprivation and mortality in Glasgow, Liverpool and Manchester. ${ }^{2}$

**Includes the following categories: White and Black Caribbean; White and Black African; White and Asian; Any other mixed or multiple ethnic groups ; Indian; Pakistani; Bangladeshi; Chinese; Any other Asian background; African; Caribbean; Black; Any other Black/African/Caribbean background; Arab; Any other ethnic group.

t†ln analysing the data it seemed important to distinguish the views of those who had been resident in their city for a long time and those who had not. However, no specific question on length of residence in the city was included in the survey. Thus, a crude measure of likely length of residence was derived from other available information: respondents were asked how long they had lived in their neighbourhood (with options ranging from 'under six months' to 'over five years'), and those who lived through the 1980 s (ie, were aged at least 36 at the time of the survey) were additionally asked in which city they were resident for most of that decade. From those two questions, respondents were categorised as being 'Possibly long-term resident' (based on either being resident in their neighbourhood for 5 years or more, or having been in the same city in the 1980s) or 'length of residence in city unknown'.

FT, full time; NVQ/SVQ, National Vocational Qualifications Scottish Vocational Qualifications; PT, part time. 
Table 2 Multivariate linear regression analysis of the factors associated with Sense of Coherence (SOC-13) score

\begin{tabular}{|c|c|c|c|c|}
\hline Variable/category & $\begin{array}{l}\text { N } \\
\text { (weighted) }\end{array}$ & $\begin{array}{l}\text { Adjusted } \\
\text { mean* }^{*}\end{array}$ & $\Delta \mu \dagger(95 \% \mathrm{Cl})$ & $\begin{array}{l}\text { Significance, } \\
\text { p value }\end{array}$ \\
\hline \multicolumn{5}{|l|}{ City } \\
\hline Glasgow $\ddagger$ & 1288 & 65.12 & & \\
\hline Liverpool & 1193 & 60.07 & $-5.05(-6.04$ to -4.07$)$ & $<0.001$ \\
\hline Manchester & 1216 & 56.98 & $-8.14(-9.12$ to -7.16$)$ & $<0.001$ \\
\hline \multicolumn{5}{|l|}{ Deprivation quintile } \\
\hline 1 (most deprived)‡ & 668 & 65.12 & & \\
\hline 2 & 716 & 65.83 & $0.71(-0.60$ to 2.02$)$ & 0.289 \\
\hline 3 & 723 & 66.37 & $1.25(-0.07$ to 2.57$)$ & 0.064 \\
\hline 4 & 802 & 67.59 & 2.47 (1.16 to 3.78$)$ & $<0.001$ \\
\hline 5 (least deprived) & 788 & 67.71 & 2.59 (1.26 to 3.93$)$ & $<0.001$ \\
\hline \multicolumn{5}{|l|}{ Educational attainment } \\
\hline No qualifications $\ddagger$ & 1148 & 65.12 & & \\
\hline Some qualifications, but not degree level & 2019 & 67.81 & 2.69 (1.67 to 3.71$)$ & $<0.001$ \\
\hline $\begin{array}{l}\text { 1st degree and above (includes NVQ/SVQ level } 5 \\
\text { or equivalent) }\end{array}$ & 531 & 69.57 & 4.45 (3.00 to 5.90$)$ & $<0.001$ \\
\hline \multicolumn{5}{|l|}{ Employment status } \\
\hline Employed (PT and FT)‡ & 1428 & 65.12 & & \\
\hline Unemployed & 442 & 58.33 & $-6.79(-8.17$ to -5.40$)$ & $<0.001$ \\
\hline III/disabled & 245 & 54.26 & $-10.86(-12.62$ to -9.10$)$ & $<0.001$ \\
\hline Retired & 698 & 66.47 & $1.35(-0.43$ to 3.13$)$ & 0.136 \\
\hline Looking after home/family & 351 & 64.06 & $-1.06(-2.55$ to 0.43$)$ & 0.162 \\
\hline In education/training (PT/FT) & 509 & 65.22 & $0.10(-1.35$ to 1.55$)$ & 0.892 \\
\hline \multicolumn{5}{|l|}{ Marital status } \\
\hline Never married $\ddagger$ & 1671 & 65.12 & & \\
\hline Married/civil partnership & 1416 & 67.36 & 2.24 (1.13 to 3.35$)$ & $<0.001$ \\
\hline Separated/divorced & 339 & 65.48 & $0.36(-1.26$ to 1.98$)$ & 0.662 \\
\hline Widowed/surviving partner & 271 & 65.58 & $0.46(-1.57$ to 2.49$)$ & 0.658 \\
\hline \multicolumn{5}{|l|}{ Age group } \\
\hline $16-29 \ddagger$ & 1255 & 65.12 & & \\
\hline $30-44$ & 908 & 63.65 & $-1.47(-2.70$ to -0.24$)$ & 0.019 \\
\hline $45-64$ & 958 & 64.07 & $-1.05(-2.43$ to 0.33$)$ & 0.137 \\
\hline $65+$ & 569 & 65.99 & $0.87(-1.30$ to 3.05$)$ & 0.432 \\
\hline \multicolumn{5}{|c|}{$\begin{array}{l}\mathrm{R}^{2}=0.18 ; \text { adjusted } \mathrm{R}^{2}=0.18 \text {. } \\
\text { *Mean predicted by full fitted model. } \\
\text { †Difference in mean compared to reference category after adjustment for other factors in the model. } \\
\text { †Reference category of variable. } \\
\text { FT, full time; NVQ/SVQ, National Vocational Qualifications Scottish Vocational Qualifications; PT, part time. }\end{array}$} \\
\hline
\end{tabular}

Glasgow after adjustment for other factors in the model; however, there was no difference between the Glasgow and Liverpool samples. ${ }^{\text {ix }}$ The addition of SoC to the model showed that, after adjustment for other factors, a one unit increase in SoC was associated with an approximately $3 \%$ lower likelihood of reporting bad or very bad health (OR 0.97 (95\% CI 0.96 to 0.98)). Although differences in SoC therefore explained some of the difference in SAH across the sample overall, high SoC and (paradoxically) slightly worse $\mathrm{SAH}$ in the Glasgow sample meant that adjustment for SoC in the model reduced the odds of reporting worse SAH among those in Liverpool and Manchester (compared to Glasgow),

${ }^{\mathrm{ix}}$ ORs Manchester 0.67 (95\% CIs 0.48 to 0.94$)$; Liverpool $0.74(95 \%$ CIs 0.54 to 1.02 ). despite increasing (slightly) the total amount of variation explained (as measured by $\mathrm{R}^{2}$ statistic). These results are shown in table 3 .

\section{DISCUSSION}

Overall findings and implications

Based on representative samples of three UK cities and contrary to the hypothesis, SoC appears to be markedly higher, not lower, among Scottish (Glasgow) compared to English (Liverpool, Manchester) populations.

Although based on cross-sectional survey data which do not allow any measure of impact, or otherwise, on individuals' subsequent mortality, the results nonetheless suggest that $\mathrm{SoC}$ is an unlikely explanatory factor for the excess mortality recorded in the Scottish city compared to the two English cities and, by extension, that seen in Scotland compared to England and Wales. 
Table 3 Multivariate logistic regression analysis: ORs for residents of Liverpool and Manchester, compared to those of Glasgow, for reporting bad or very bad health, after adjustment for (1) characteristics of the samples and (2) Sense of Coherence (SOC-13) score

\begin{tabular}{|c|c|c|c|c|}
\hline Model & City & Percentage of sample* $^{*}$ & OR (fully adjusted; 95\% CI) & Sigt, $p$ value \\
\hline \multicolumn{5}{|c|}{$\begin{array}{l}1 \text { Adjusting for age, gender, social grade, employment status, educational attainment, deprivation quintile, ethnicity, marital } \\
\text { status, length of residence in city }\end{array}$} \\
\hline & Glasgow $\ddagger$ & 9.6 & & \\
\hline & Liverpool & 8.5 & 0.74 (0.54 to 1.02$)$ & 0.065 \\
\hline & Manchester & 5.9 & 0.67 (0.48 to 0.94$)$ & 0.022 \\
\hline \multicolumn{5}{|c|}{2 Adjusting for the above, plus Sense of Coherence (SoC-13) $\dagger$} \\
\hline & Glasgowł & 9.6 & & \\
\hline & Liverpool & 8.5 & 0.67 (0.48 to 0.93$)$ & 0.016 \\
\hline & Manchester & 5.9 & $0.53(0.38$ to 0.76$)$ & $<0.001$ \\
\hline
\end{tabular}

\section{Strengths and weaknesses}

The study has a number of strengths. This is the first time SoC has been measured for these three, important, urban centres in the UK, using a scale deemed reliable and valid. The analyses were based on a survey the response rate for which was far better than that achieved in many other local, ${ }^{41}{ }^{42}$ regional $^{43-45}$ and even national $^{46} \quad 47$ surveys, and-as discussed elsewhere ${ }^{33}$ this relatively high rate was obtained across all neighbourhood types (deprived and non-deprived) in all three cities. The data have been shown to be broadly representative of the cities' populations, while all the analyses that were undertaken entailed a multivariate regression modelling component, ensuring that any reported differences between the cities were independent of the characteristics of the survey samples.

There are also a number of weaknesses associated with this study which must be acknowledged. As stated, the analyses have been based on cross-sectional survey data which do not, therefore, allow any measure of impact, or otherwise, on individuals' subsequent mortality (an important component of the original hypothesis). Any population survey, especially one based on such a sample size and with an overall $55 \%$ response rate, is unlikely to be entirely representative of its target population: we have to be aware that it is probable that not all sections of society are represented within the collected data. As stated, the extent to which SOC-13 accurately captures the concept of SoC has been debated by some.

\section{Relevance to other studies}

This is the first time that SoC has been measured in these UK cities, and it is difficult and potentially misleading to compare SoC scores between different surveys, given the different population characteristics, socioeconomic conditions, sampling methodologies, sample sizes and response rates that may apply. With those caveats in mind, however, it is still potentially useful to know how the scores obtained in this study compare with those reported elsewhere.

A series of systematic reviews of the SoC scale was undertaken by Eriksson and Lindström between 2005 and 2007. ${ }^{13}{ }^{14}{ }^{16}$ From 127 studies published between 1992 and 2003, the mean score for the 13-item SoC scale (SOC-13) ranged from 35.4 to 77.6. Very low scores were obtained from particular subgroups of populations, for example 35.4 from a group of Norwegian substance abusers, ${ }^{48} 53.3$ for a group of people suffering from schizophrenia who were unemployed in Sweden ${ }^{49}$ and 59.9 for American single parents of disabled children. ${ }^{50}$ There have been relatively few studies of the general population, and many of those had small samples. The resulting population estimates therefore ranged widely from 59 in the Canadian general population in $1999^{51}$ to 70.8 in the Swedish population in $2002 .{ }^{52}$ It is difficult to assess, therefore, whether the scores obtained in this study for residents of Glasgow (67.6), Liverpool (63.1) and Manchester (59.3) are high or low compared to other populations. That said, however, a more recent (2010), large-scale $(n>43500)$, study of the general population by Nilsson et a $e^{53}$ obtained a score of 68.5 (SD 12.75) for the population of five Swedish countiesa figure similar to that of Glasgow and, therefore, higher than that of the English cities. Finally, the Glasgow score is further validated by a 2012 study $^{54}$ which measured SoC among deprived and affluent groups in the city, and found fairly similar results: the SOC-13 score was 59.6 for the deprived group and 70.3 for the affluent group, which are not markedly different from the scores of 61.9 (95\% CI 59.9 to 63.4 ) and 72.2 (95\% CI 69.9 to 74.4) for the lowest and highest socioeconomic groups in the Glasgow sample here.

These three-city analyses confirm the association between SOC and various measures of SES ${ }^{55-58}$ and also, independently, marital status. ${ }^{59}$ They additionally provide further evidence for SoC as an independent predictor of differences in general health status, ${ }^{16}$ with a 
one unit increase in SoC associated with around a 3\% lower likelihood of reporting bad/very bad health (albeit that the addition of SoC did not greatly increase the amount of variation explained in the model). Of course they also present a paradox: given the proven link between SoC and health, why should SoC be relatively 'better' in a population associated with relatively 'worse' mortality? Different interpretations are possible. First, it may suggest weaknesses in the extent to which the SOC-13 scale fully captures the concept of SoC, being perhaps vulnerable to cultural influences in selfreporting in the same way some measures of selfreported health status have been shown to be. ${ }^{39-41}$ Although, as stated, the measure has been judged 'cross-culturally applicable', other recent research has suggested the manner in which SoC operates within different cultures is not entirely clear and requires further research. ${ }^{60}$ Second, it may suggest the survey samples are flawed and unrepresentative; more specifically, as population surveys may not reach those at the greatest risk of early death, it could be that, among those omitted, a different SoC profile could apply. However, the survey samples have in fact been shown to be broadly representative of all three cities; ${ }^{33}$ furthermore, mortality is higher in Glasgow compared to the English cities across the whole social spectrum, and in the survey SoC was also shown to be higher in comparisons of all social classes. This, therefore, seems an unlikely explanation.

The results suggest the need for further research into this paradox-although in many cases, potential areas of enquiry are currently hampered by a lack of available, comparable, data. For example, some commentators have highlighted the need to differentiate between individual and community SoC (and related attributes): it has been suggested that high levels of the latter may be associated with protective effects for example, where particular communities counter perceived discrimination or threat with a greater collective strength and sense of identity. ${ }^{61-63}$ A study into differences between these two forms of SoC across the three UK cities might, therefore, prove instructive. Similarly, research could be undertaken into differences in greater generalised resistance resources (GRRs). GRRs are another concept introduced by Antonovsky: they include factors like coping strategies, social support and knowledge which are deemed to reinforce and strengthen SoC in individuals. ${ }^{11}$ Finally, recent research has suggested that a considerable amount of variation in individual SoC can be explained by genetic factors; ${ }^{64}$ however, no suitable data for these cities are available to investigate this further.

\section{CONCLUSIONS}

The reasons for the high, and increasing, levels of 'excess' mortality seen in Scotland, and particularly in its largest city, remain unclear. However, on the basis of these analyses, it appears unlikely that a low SoC in Glasgow or Scotland provides any explanation.
Acknowledgements This work would not have been possible without the co-operation, participation and assistance of a number of individuals and organisations. The authors would like to thank, first and foremost, all the survey respondents in Glasgow, Liverpool and Manchester for giving up their time to complete the questionnaire. The authors also thank the following for their help, time and efforts: Jo Christensen, Paul Murphy, Jeremy Hardin and Jodie Knight at AECOM Social and Market Research; Ruth McLaughlin, formerly of GCPH, for initial work in the development of the questionnaire; Catherine Ferrell at the MRC/CSO Social and Public Health Sciences Unit, University of Glasgow, for help and insights in commissioning the survey; David Regan, Public Health Manchester, and Paula Grey, Liverpool Primary Care Trust, as well as Colin Cox (Public Health Manchester), Julia Taylor (formerly of Liverpool Primary Care Trust and Liverpool Healthy Cities) and Alison Petrie-Brown (Liverpool Primary Care Trust), for invaluable help in encouraging local participation in the survey; Phil Mason, Mark Livingston and Maria Gannon, University of Glasgow, for additional statistical support and advice; Avishai Antonovsky, Open University Israel, for permission (granted to AECOM) to use the Sense of Coherence (SoC-13) survey scale.

Contributors DW, GM, SM and RJ were involved in the initial conception and design of the study, including the commissioning and specification of the survey, and drawing up of research questions. DW acquired and prepared the data set, and undertook all analyses, with support from DB and GM. DW drafted the manuscript. All authors provided substantial critical input to improve the manuscript and all authors approved the final draft.

Funding The survey was jointly funded by NHS Health Scotland and the Glasgow Centre for Population Health.

\section{Competing interests None.}

Ethics approval The survey was approved by the University of Glasgow Medical Faculty Ethics Committee (project reference no. zFM06910).

Provenance and peer review Not commissioned; externally peer reviewed.

Data sharing statement No additional data are available.

Open Access This is an Open Access article distributed in accordance with the Creative Commons Attribution Non Commercial (CC BY-NC 4.0) license, which permits others to distribute, remix, adapt, build upon this work noncommercially, and license their derivative works on different terms, provided the original work is properly cited and the use is non-commercial. See: http:// creativecommons.org/licenses/by-nc/4.0/

\section{REFERENCES}

1. Hanlon $P$, Lawder RS, Buchanan $D$, et al. Why is mortality higher in Scotland than in England \& Wales? Decreasing influence of socioeconomic deprivation between 1981 and 2001 supports the existence of a 'Scottish Effect'. J Public Health (Oxf) 2005;27:199-204.

2. Walsh D, Bendel N, Jones R, et al. It's not 'just deprivation': why do equally deprived UK cities experience different health outcomes? Public Health 2010;124:487-95.

3. Walsh D, Bendel N, Jones R, et al. Investigating a 'glasgow effect': why do equally deprived UK cities experience different health outcomes? Glasgow: GCPH, 2010.

4. Popham F, Boyle PJ. Is there a 'Scottish effect' for mortality? Prospective observational study of census linkage studies. J Public Health 2011;33:453-8.

5. Popham F, Boyle PJ, Norman P. The Scottish excess in mortality compared to the English and Welsh. Is it a country of residence or country of birth excess? Health Place 2010;16:759-62.

6. McCartney G, Russ T, Walsh D, et al. Explaining the excess mortality in Scotland compared with England: pooling of 18 cohort studies. J Epidemiol Community Health 2014. doi:10.1136/jech2014-204185.

7. McCartney G, Collins C, Walsh D, et al. Accounting for Scotland's excess mortality: towards a synthesis. Glasgow: GCPH, 2011.

8. McCartney G, Collins C, Walsh D, et al. Why the Scots die younger: synthesizing the evidence. Public Health 2012;126:459-70.

9. Scottish Government. Health in Scotland 2008-Annual Report of the Chief Medical Officer. Edinburgh: Scottish Government, 2009. 
10. Scottish Government. Health in Scotland 2009 Time for changeAnnual Report of the Chief Medical Officer. Edinburgh: Scottish Government, 2010.

11. Antonovsky A. Health, stress and coping. San Francisco: Jossey-Bass, 1979

12. Antonovsky A. Unravelling the mystery of health. How people manage stress and stay well. San Francisco: Jossey-Bass, 1987.

13. Eriksson M, Lindström B. Validity of Antonovsky's sense of coherence scale: a systematic review. J Epidemiol Community Health 2005;59:460-6.

14. Eriksson M, Lindström B. Antonovsky's sense of coherence scale and its relation with quality of life: a systematic review. J Epidemiol Community Health 2007;61:938-44.

15. Van Leeuwen CMC, Kraaijeveld S, Lindeman E, et al. Associations between psychological factors and quality of life ratings in persons with spinal cord injury: a systematic review. Spinal Cord 2012;50:174-87.

16. Eriksson M, Lindström B. Antonovsky's sense of coherence scale and the relation with health: a systematic review. J Epidemiol Community Health 2006:60:376-81.

16a. Flensborg-Madsen T, Ventegodt S, Merrick J. Sense of Coherence and Physical Health. A Review of Previous Findings. The Scientific World Journal 2005;5:665-73.

17. Coward D. Self-transcendence and correlates in a healthy population. Nurs Res 1996;45:116-21.

18. Edwards D, Besseling E. Relationship between depression, anxiety, sense of coherence, social support and religious involvement in a small rural community affected by industrial relations conflict. South Afr J Psychol 2001;31:62-72.

19. Gibson LM. Inter-relationships among sense of coherence, hope, and spiritual perspective (inner resources) of African-American and European-American breast cancer survivors. Appl Nurs Res 2003;16:236-44.

20. Matsuura E, Ohta A, Kanegae F. et al. Frequency and analysis of factors closely associated with the development of depressive symptoms in patients with scleroderma. $J$ Rheumatol 2003;30:1782-7.

21. Eriksson NG, Lundin T. Early traumatic stress reactions among Swedish survivors of the $\mathrm{m} / \mathrm{s}$ Estonia disaster. Br J Psychiatry 1996;169:713-16.

22. Kouvonen AM, Vaananen A, Vahtera J, et al. Sense of coherence and psychiatric morbidity: a 19-year register-based prospective study. J Epidemiol Community Health 2010;64:255-61.

23. Sjostrom N, Hetta J, Waern M. Sense of coherence and suicidality in suicide attempters: a prospective study. J Psychiatr Ment Health Nurs 2012;19:62-9.

24. Ristkari T, Sourander A, Ronning JA, et al. Sense of coherence and criminal offences among young males. Findings from the Finnish 1981 Nationwide Birth Cohort Follow-Up Study. European Child and Adolescent Psychiatry Conference: 14th International Congress of ESCAP European Society for Child and Adolescent Psychiatry, Helsinki, Finland, 2011

25. Glanz K, Maskarinec G. Ethnicity, sense of coherence, and tobacco use among adolescents. Ann Behav Med 2005;29:192-9.

26. Nilsson KW, Starrin B, Simonsson B, et al. Alcohol-related problems among adolescents and the role of a sense of coherence. Int J Soc Welf 2007;16:159-67.

27. Arevalo S, Prado G, Amaro H. Spirituality, sense of coherence, and coping responses in women receiving treatment for alcohol and drug addiction. Eval Program Plann 2008;31:113-23.

28. Lundberg O, Peck MN. Sense of coherence, social structure and health. Evidence from a population survey in Sweden. Eur J Public Health 1994:4:252-7.

29. Agardh EE, Ahlbom A, Andersson T, et al. Work stress and low sense of coherence is associated with type 2 diabetes in middle-aged Swedish women. Diabetes Care 2002;26:719-24.

30. Ristner G, Andersson R, Johansson LM, et al. Sense of coherence and lack of control in relation to outcome after orthopaedic injuries. Injury 2000;31:751-6.

31. Ray EC, Nickels MW, Sayeed S, et al. Predicting success after gastric bypass: the role of psychosocial and behavioral factors. Surgery 2003;134:555-64.

32. Wainwright NWJ, Surtees PG, Welch AA, et al. Sense of coherence, lifestyle choices and mortality. J Epidemiol Community Health 2008:62:829-31.

33. Walsh D, McCartney G, McCullough S, et al. Exploring potential reasons for Glasgow's 'excess' mortality: results of a three-city survey of Glasgow, Liverpool and Manchester. Glasgow Centre for Population Health, 2013. http://www.gcph.co.uk/publications/440_ exploring potential reasons_for glasgows excess mortality (accessed Dec 2013).
34. AECOM Social and Market Research. Investigating the 'Glasgow Effect'-Three Cities Population Survey: Technical Survey Report. February 2012. http://www.healthscotland.com (accessed Apr 2014)

35. Phillimore P. How do places shape health? Rethinking locality and lifestyle in N-E England. Paper Presented at British Sociological Association Annual Meeting; Manchester, April 1991.

36. Andrews GJ, Moon G. Space, place, and the evidence base: part -an introduction to health geography. Worldviews Evid Based Nurs 2005;2:55-62.

37. Fone DL, Dunstan F. Mental health, places and people: a multilevel analysis of economic inactivity and social deprivation. Health Place 2006;12:332-44.

38. OECD. Self-reported health and disability. In: OECD. Health at a Glance: Europe 2010. Paris: OECD Publishing, 2010:44-5.

39. Jürges $\mathrm{H}$. True health vs. response styles: exploring cross-country differences in self-reported health. Health Econ 2007;16:163-78.

40. O'Reilly D, Rosato M. Dissonances in self-reported health and mortality across denominational groups in Northern Ireland. Soc Sci Med 2010;71:1011-17

41. EURO-URHIS 2: European Urban Health Indicators System Part 2. Health profile: Glasgow (Adult survey). EURO URHIS 2012. http:// results.urhis.eu/profiles/HealthProfile_Glasgow\%2025082012.pdf (accessed Apr 2013)

42. Kirkcaldy A, Robinson J, Barr W. The Liverpool And Sefton Lifestyle Survey. Report No. 94/03. Health and Community Care Research Unit, 2003. http://www.liv.ac.uk/haccru/backup/reports/Liverpool and_South_Sefton_Lifestyle_Survey.pdf (accessed Apr 2013).

43. NHS Forth Valley. Adult Health and Lifestyle Survey. NHS Forth Valley, 2004. http://www.nhsforthvalley.com/ documents/ health-services/audiology/services/public-helath/adult_health_and lifestyle survey 05.pdf (accessed Apr 2013).

44. Barr W, Kirkcaldy A, Greater Merseyside Lifestyle Survey. Report No. 96/04. Health and Community Care Research Unit, 2004. http:// www.heartofmersey.org.uk/cms useruploads/files/hm Illis greater merseyside_lifestyle_s.pdf (accessed Apr 2013).

45. NHS Sefton Lifestyle Survey 2010. http://www.seftonpct.nhs.uk/ your-health/public-health-information/Lifestyle survey_results.asp (accessed Apr 2013)

46. Office for National Statistics (ONS). Labour Force Survey: Performance and Quality Monitoring Report, October to December 2012. http://www.ons.gov.uk/ons/guide-method/method-quality/ specific/labour-market/labour-force-survey/pqm-report-octoberdecember-2012.pdf (accessed Feb 2013).

47. Hossack P, Jarvis E. Living Costs and Food Survey. Technical Report for survey year: January-December 2010. Newport: Office for National Statistics, 2012.

48. Berg JE, Brevik JI. Complaints that predict drop-out from a detoxification and counselling unit. Addict Behav 1998;23:35-40.

49. Eklund M, Hansson L, Bejerholm U. Relationships between satisfaction with occupational factors and health-related variables in schizophrenia outpatients. Soc Psychiatry Psychiatr Epidemiol 2001;36:79-83.

50. Gottlieb A. Single mothers of children with disabilities. The role of sense of coherence in managing multiple challenges. In: McCubbin $\mathrm{HI}$, Thompson EA, Thompson AI, Fromer JE, eds. Stress, coping, and health in families: sense of coherence and resiliency. Thousand Oaks, CA, USA: Sage Publications, 1998:189-204.

51. Wolff AC, Ratner PA. Stress, social support, and sense of coherence. West J Nurs Res 1999;21:182-97.

52. Nilsson B, Holmgren L, Stegmayr B, et al. Sense of coherencestability over time and relation to health, disease, and psychosocial changes in a general population: a longitudinal study. Scand $J$ Public Health 2003;31:297-304.

53. Nilsson KW, Leppert J, Simonsson B, et al. Sense of coherence and psychological well-being: improvement with age. J Epidemiol Community Health 2010:64:347-52.

54. Packard CJ, Cavanagh J, McLean JS, et al. Interaction of personality traits with social deprivation in determining mental wellbeing and health behaviours. J Public Health 2012;34:615-24

55. Larsson G, Kallenberg KO. Sense of coherence, socioeconomic conditions and health: interrelationship in a nation-wide Swedish sample. Eur J Public Health 1996;6:175-80.

56. Lundberg $\mathrm{O}$. 'Sense of coherence' och befolkningens hälsa. Sos Laaketiet Aikak 1996;33:265-73.

57. Kalimo R, Vuori J. Work and sense of coherence: resources for competence and life satisfaction. Behav Med 1990;16:76-89.

58. Ing JD, Reutter $\mathrm{L}$. Socioeconomic status, sense of coherence and health in Canadian women. Can J Public Health 2003;94:224-8.

59. Volanen SM, Lahelma E, Silventoinen $\mathrm{K}$, et al. Factors contributing to sense of coherence among men and women. Eur J Public Health 2004;14:322-30. 
60. Eriksson M. Sagy S. Lindström B. A salutogenic perspective on mental health across the life time. Cultural aspects on the sense of coherence. In: Mayer $\mathrm{CH}$, Krause C. Exploring mental health: theoretical and empirical discourses on salutogenesis. Lengerich: Pabst Publishers, 2012145-60.

61. Braun-Lewensohn O, Sagy S. Salutogenesis and culture: personal and community sense of coherence among adolescents belonging to three different cultural groups. Int Rev Psychiatry 2011;23:533-41.

62. Braun-Lewensohn O, Sagy S. Community resilience and sense of coherence as protective factors in explaining stress reactions: comparing cities and rural communities during missiles attacks. Community Ment Health J 2014;50:229-34.

63. Birman D, Trickett E, Buchanan RM. A tale of two cities: replication of a study on the acculturation and adaptation of immigrant adolescents from the former Soviet Union in a different community context. Am J Community Psychol 2005;35:83-101.

64. Silventoinen K, Volanen SM, Vuoksimaa E, et al. A supportive family environment in childhood enhances the level and heritability of sense of coherence in early adulthood. Soc Psychiatry Psychiatr Epidemiol 2014. doi:10.1007/s00127-014-0851-y 